\title{
Biologia de nidificação de Anthodioctes megachiloides Holmberg (Anthidiini, Megachilidae, Apoidea)
}

\author{
Isabel Alves-dos-Santos \\ Diretoria de Pós-graduação, Universidade do Extremo Sul Catarinense. Caixa Postal 3167, 88806-000 Criciúma, Santa \\ Catarina, Brasil.
}

\begin{abstract}
Nesting biology of Anthodioctes megachiloides Holmberg (Anthidiini, Megachilidae, Apoidea). Anthodioctes megachiloides Holmberg 1903 is a solitary bee that uses pre-existing cavities to construct the nest. Wood trap-nests were installed on the garden of the Bee Laboratory at the University Campus in São Paulo. The traps consisted of circular holes 4 to $5 \mathrm{~mm}$ in diameter, drilled 5 to $7 \mathrm{~cm}$ deep. Rolled papers were inserted in the hole, so that the paper tube could later and periodically be inspected. Data on the biology, nest construction, female behaviour and parasites activity were gathered through direct observation during the spring and summer seasons of 2001/2002. Females of $A$. megachiloides began their activity in middle August and funded in total 40 nests on the spring 2001. Plant resin is used to coat the cells, construct the partitions and nest-closure. Of 24 nests examined, 18 contained dead immature, indicating that mortality was high. One species of Sapygidae wasp was detected as cleptoparasite of $A$. megachiloides.
\end{abstract}

KEY WORDS. Parasitism, solitary bee, southeastern Brazil, trapnest.

RESUMO. Anthodioctes megachiloides Holmberg, 1903 é uma abelha solitária que utiliza cavidades pré-existentes para construir o ninho. Ninhos armadilhas de madeira foram instalados no jardim do Laboratório de Abelhas no campus da Universidade de São Paulo. As armadilhas consistiram de orifícios circulares de 4 a $5 \mathrm{~mm}$ de diâmetro, com profundidade de $5 \mathrm{a} 7 \mathrm{~cm}$. Tubos de papel foram inseridos nos orifícios de tal maneira que pudessem ser posteriormente e periodicamente inspecionados. Dados sobre a biologia, construção de ninho, comportamento da fêmea e atividade dos parasitas foram obtidas através de observações diretas durante a primavera e verão de 2001/2002. Fêmeas de $A$. megachiloides iniciaram atividade em meados de agosto e fundaram um total de 40 ninhos na primavera de 2001. Resina vegetal é usada para cobrir as células, construir as partições e fechamento do ninho. De 24 ninhos examinados, 18 continham imaturos mortos, indicando que a taxa de mortalidade foi alta. Uma espécie de vespa da família Sapygidae foi detectada como cleptoparasita de $A$. megachiloides.

PALAVRAS CHAVE. Abelha solitária, ninhos armadilha, parasitismo, sudeste do Brasil.

Fêmeas de abelhas solitárias são fecundadas logo após emergirem e em seguida iniciam a busca pelo local do ninho e sua construção; podendo para isso cavar ou utilizar cavidades pré-existentes em árvores, muros, barrancos ou galerias de ninhos abandonados (Krombein 1967, Camillo et al. 1995). Após encontrar um local apropriado, a fêmea inicia uma série de tarefas como, por exemplo, coleta de material de construção, coleta de alimento para aprovisionar as células e defesa do ninho (Alves dos SANTos 2002).

A reutilização do ninho parental é relativamente comum entre as abelhas solitárias que formam agregações (RoubIK 1989). Neste caso, as fêmeas procuram locais para nidificar próximo aos ninhos antigos, mantendo muitas vezes perene a área de agregação da espécie. A oferta artificial de ninhos próximos à agregação pode ser bem sucedida, pois irá absorver muitas das fêmeas nidificantes (KoERBEL \& MEDler 1958, TsCHARNTKE et al. 1998).
Abelhas da família Megachilidae utilizam cavidades préexistentes com alta frequência (KROMBein 1967, EicKwort et al. 1981, Camillo et al. 1983, 1994, Frohlich 1983, Parker 1987, Torchio 1989, Bosch et al. 1993). A facilidade de se obter o ninho em armadilhas permitiu ampliar o conhecimento da biologia de várias espécies de Megachilidae e o domínio da técnica de criação e produção em grande escala. Atualmente algumas espécies são comercializadas para polinização. Abelhas do gênero Osmia Panzer, 1806, por exemplo, são utilizadas na polinização de várias espécies frutíferas, o que as tornaram popularmente conhecidas como "abelhas do pomar"- orchad bees (Torchio 1976). Megachile rotundata Fabricius, 1787 é utilizada na polinização de extensas plantações de alfafa e outras leguminosas (RichARDs 1984, 1993). Entre as tribos de Megachilidae, relativamente poucos trabalhos tratam da biologia da nidificação dos membros da tri- 
bo Anthiidini (Krombein 1967, Grigarick \& Stange 1968, Laroca \& Rosado Neto 1975, Parker 1987, Morato 2001, Alves dos Santos et al. in press).

Este trabalho acompanhou o processo de ocupação de ninhos-armadilhas por uma espécie de Anthidiini - Anthodioctes megachiloides Holmberg, 1903 - com o objetivo de se obter dados sobre a biologia e hábitos de nidificação desta espécie.

\section{MATERIAL \& MÉTODOS}

Este estudo foi realizado no jardim do Laboratório de Abelhas do Instituto de Biociências, na cidade Universitária em

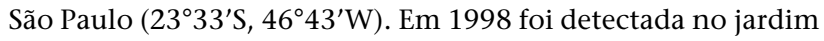
a presença de ninhos de algumas espécies de abelhas e vespas, entre elas A. megachiloides, em troncos perfurados por besouros. A partir de novembro de 1998 iniciou-se um acompanhamento mais metódico sobre a atividade dos ocupantes. Foram oferecidas armadilhas próximas aos troncos para ampliar as possibilidades de ocupação. Resultados deste estudo podem ser encontrados em Alves-dos-SANTOS (2003). O clima em São Paulo é classificado como subtropical, com um inverno bem definido, frio e seco. A estação chuvosa se concentra no verão.

Os ninhos-armadilha foram feitos em blocos de madeiras com orifícios de 4-5 mm diâmetro e 5-7 cm de comprimento. Os orifícios foram providos com um tubo de papel pardo, que permitiu sua retirada periodicamente para inspeção e coleta de material. Foram oferecidos 112 ninhos armadilha deste tipo, que foram instalados no início da primavera, em setembro de 2001 e inspecionados até maio de 2002. Os blocos de madeiras e os conjuntos de ninhos-armadilha estiveram dispostos em local protegido da chuva e sol direto.

Os ninhos fundados por $A$. megachiloides foram registrados e acompanhados por observação direta, quanto ao movimento e comportamento das fêmeas ocupantes. Algumas fêmeas foram marcadas com tinta Revell Color, para individualizá-las e melhor acompanhar suas atividades diárias. Um oftalmoscópio permitiu inspeção da atividade interna do ninho, sem abri-lo.

Para obtenção de dados sobre o desenvolvimento larval e arquitetura interna, 24 ninhos de $A$. megachiloides fundados no local em abril de 2001 foram retirados para inspeção e acompanhamento. Além disso, 22 ninhos foram retirados entre setembro de 2001 e abril de 2002 após seu fechamento e mantidos sob observação da mesma maneira no Laboratório.

Adultos e ninhos foram conservados secos, e imaturos em solução de hidróxido de potássio. O material coletado encontra-se depositado na coleção de referência do Laboratório de Abelhas do IBUSP.

\section{RESULTADOS}

Fêmeas de Anthodioctes megachiloides (Fig. 1) fundaram no total 40 ninhos na primavera e verão de 2001/2002. O início da atividade de $A$. megachiloides se deu em 15 de agosto de 2001, com o nascimento das primeiras fêmeas provenientes de ninhos anteriores fundados no mesmo local.

\section{A atividade das fêmeas}

As fêmeas estiveram ativas durante todo o dia, sendo que seu pico de atividade ocorreu entre 10:00 e 16:00. Durante este período realizaram várias viagens para coleta de pólen e resina. As coletas de resina são perfeitamente visíveis já que, este material é trazido nas mandíbulas de maneira volumosa. Estas viagens duraram entre 2 a 20 minutos, e após o retorno as fêmeas permaneceram em média $15( \pm 8,2 ; \mathrm{n}=10)$ minutos manuseando este produto dentro do ninho, que é utilizado na construção do ninho. As viagens de coleta de pólen duraram entre 4 a 7 minutos, e o descarregamento deste produto é rápido, muitas vezes durou apenas um minuto. Com o oftalmoscópio pode-se observar a fêmea retirando o pólen da escopa abdominal com as pernas traseiras e manuseando este produto dentro do ninho. Várias viagens para coleta de pólen são realizadas seqüencialmente para atingir o volume necessário de cada célula, que preenche cerca da metade do volume da célula. A massa de pólen é viscosa a quase líquida, demonstrando que a fêmea adiciona alguma substância ao pólen, provavelmente néctar ou alguma secreção da glândula salivar. O ovo é colocado sobre a massa de pólen.

Foi observado que freqüentemente as fêmeas visitaram seus ninhos antigos (já fechados), inspecionando com as peças bucais toda a área do fechamento. Notou-se que isso ocorreu principalmente quando a fêmea iniciou um novo ninho e no retorno dos vôos de forrageamento inspecionou primeiro o ninho antigo, antes de se dirigir para o que estava em construção.

\section{A construção do ninho}

O ninho de $A$. megachiloides foi constituído em sua maioria de duas a seis células arranjadas linearmente e geralmente um espaço vestibular antes do fechamento. Em um ninho com $7 \mathrm{~cm}$ de profundidade foram registradas seis células construídas, sendo a primeira e a penúltima vazias. Células vazias também foram registradas em outros dois ninhos. De 66 células examinadas em 15 ninhos, quatro eram vazias, perfazendo uma proporção de 16/1.

As células de A. megachiloides mediram entre 6 a $10 \mathrm{~mm}$ $(\mathrm{n}=84)$ de comprimento e o espaço vestibular entre 5 a $15 \mathrm{~mm}$ $(\mathrm{n}=21)$. Foi perceptível que em muitos ninhos as últimas células, ou seja, as mais próximas da entrada, eram as menores medindo cerca de $7 \mathrm{~mm}$. A figura 2 ilustra um ninho, que foi extraído antes de seu fechamento, contendo duas células prontas e uma em construção.

Na construção do ninho as fêmeas utilizaram principalmente resina para o revestimento interno (laterais), repartição das células e fechamento. Grãos de areias, lascas finas de madeira e pequenos pedaços de papel (retirados de ninhos adjacentes) aparecem também aderidos e misturado à resina. A repartição das células é formada por uma parede com cerca de $0,7 \mathrm{~mm}$ de espessura, enquanto a parede de fechamento pode chegar a $1 \mathrm{~mm}$. Em alguns ninhos as fêmeas construíram uma parede de resina no fundo antes de começarem a primeira célula. Em outros, elas utilizaram a própria madeira da armadilha como fundo do ni- 

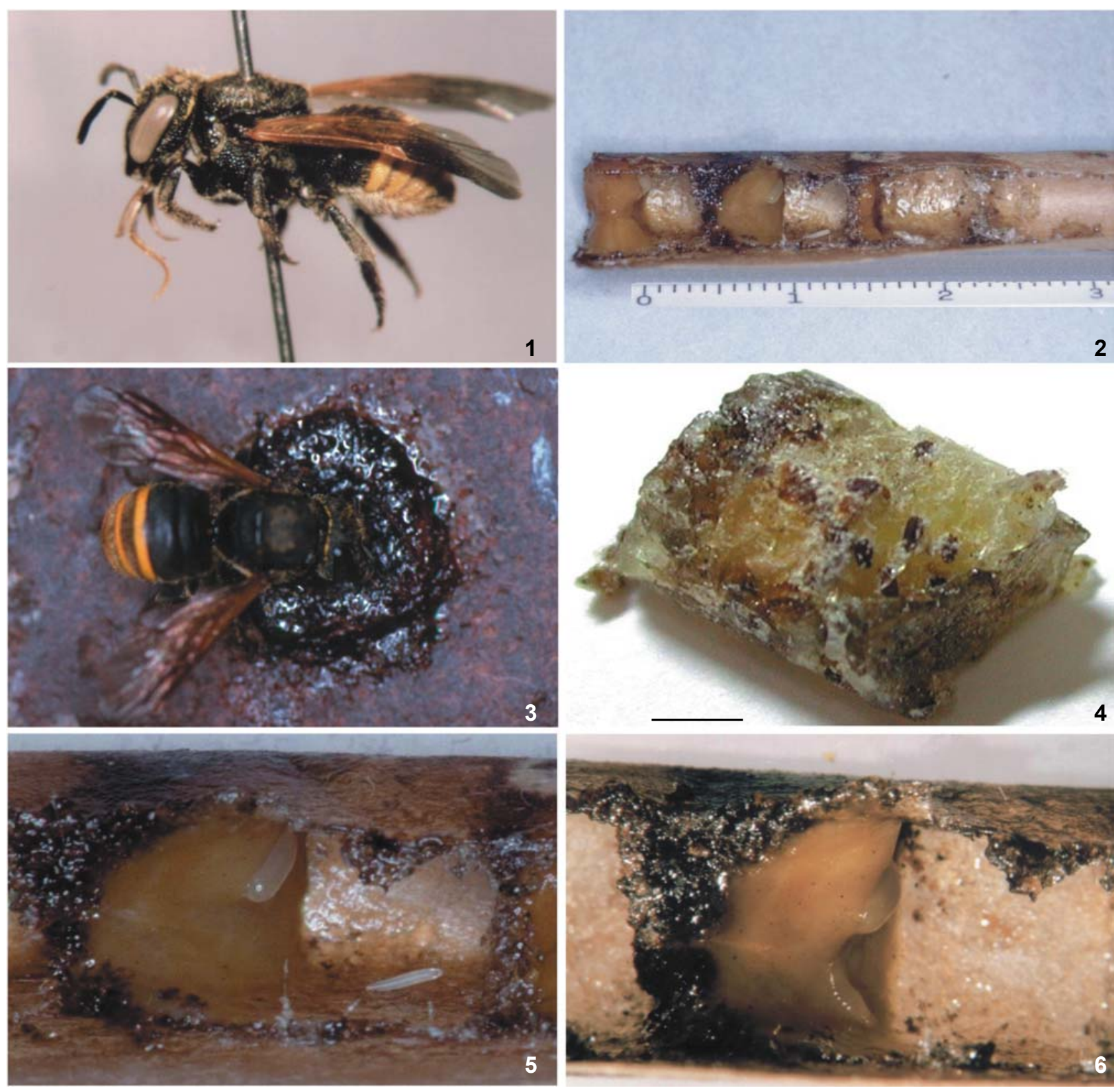

Figuras 1-6. Anthodioctes megachiloides: (1) fêmea; (2) vista interna de um ninho contendo duas células finalizadas e uma em construção; (3) fêmea finalizando o fechamento de ninho, espalhando a resina ainda elástica na superfície; (4) um casulo com algumas fezes ao redor, escala: $3 \mathrm{~mm}$; (5) uma célula contendo dois ovos (hospedeira + parasita), note a diferença no tamanho dos dois ovos; (6) a mesma célula da figura 5 um dia após tal observação. Note que parasita está no seu primeiro estágio larval e bem mais próximo do ovo da hospedeira.

nho, e iniciaram diretamente ali o depósito de pólen. Várias fêmeas construíram ninhos em orifícios pré- ou semi-ocupados por outras abelhas ou vespas. Em sete ninhos foram encontrados espécimes mortos de Tetrapedia diversipes Klug, 1810 nas células do fundo (células I e/ou II), e em dois ninhos foram encon- trados casulos de vespas, também no fundo.

Como mencionado anteriormente a resina é trazida no vôo presa às mandíbulas e depositada no local onde vai ser utilizada. A pequena bola de resina mede cerca de $2 \mathrm{~mm}$ e é macia e maleável. Ainda com as mandíbulas a fêmea estende

Revista Brasileira de Zoologia 21 (4): 739-744, dezembro 2004 
esta "bolota" e espalha ao redor. Além disso, pequenas porções de resina são depositadas em torno do orifício de entrada. Quando iniciam o processo de fechamento do ninho, as fêmeas fazem cerca de sete viagens para coleta de resina e permanecem um longo período manuseando este material na entrada (Fig. 3). As fêmeas levaram de 15-20 minutos para esticar cada "bolota" na entrada. Em um ninho fechado, a área de resina distribuída ao redor da entrada é quase o dobro do diâmetro do orifício. A resina rapidamente endurece e deixa uma aparência vitrificada no ninho fechado.

\section{Desenvolvimento e Inimigos naturais}

Após ingerir todo alimento a larva de Anthodioctes megachiloides tece um casulo. Este casulo é de cor creme a marrom clara, porém não translúcido (Fig. 4), mede entre 7-8 mm, possui uma pequena projeção apical e fica preso à parede do ninho. Em alguns ninhos observou-se que os casulos das células mais novas estavam dispostos ligeiramente oblíquos em relação à entrada do ninho. As fezes são escuras e ficam depositadas fora, ao redor de todo casulo. Em casulos propositalmente perfurados a larva imediatamente iniciou seu fechamento, tecendo os fios de um lado para o outro sobre o orifício aberto. Ninhos de A. megachiloides fechados no final do verão ou início do outono (abril-maio) permanecem sem atividade até agosto e os adultos emergem na primavera. Ninhos novos fundados no início da primavera (setembro e novembro) completam o desenvolvimento ainda no verão; somando assim pelo menos duas gerações por ano. Três ninhos de primavera acompanhados após fechamento, levaram entre 62 e 68 dias para emersão dos novos adultos.

De 24 ninhos fundados em abril de 2001 e retirados em setembro de 2001 para verificação, apenas 6 continham prépupas vivas. Os 18 restantes apresentavam imaturos mortos ou ausentes, grande quantidade de ácaros e cupins, e algumas células apresentavam-se infestadas por parasitóides do gênero Melittobia Westwood, 1848 (Eulophidae). As fêmeas deste parasitóide invadem o ninho enquanto este está sendo construído, permanecem no seu interior e depositam vários ovos sobre o imaturo. Casulos examinados de ninhos parasitados apresentaram mais de 20 ovos sobre uma pré-pupa, bem como vários indivíduos adultos dentro do casulo.

Além destes inimigos naturais foi registrada uma espécie de vespa do gênero Sapyga Latreille, 1796 (Sapygidae) com comportamento típico de espécie cleptoparasita. As fêmeas de patrulham na área e inspecionam entradas de ninhos de $A$. megachiloides. Frequentemente pousam próximo à entrada e aguardam a saída da fêmea hospedeira. Na sua ausência, entram no ninho e ovopositam. O ovo desta espécie de Sapyga é alongado e fino, branco-opaco, menor que o ovo da hospedeira e geralmente é depositado na lateral da célula (Fig. 5). O ovo de $A$. megachiloides é levemente curvado, brilhante e fica depositado sobre a massa viscosa de pólen. O primeiro estágio larval do parasita se aproxima do ovo da hospedeira antes que o mesmo ecloda (Fig. 6) para atacá-lo. Várias células examinadas conti- nham os dois ovos: da hospedeira e da parasita; demonstrando que este parasita é bem sucedido nas invasões dos ninhos.

Fêmeas de Austrostelis iheringi (Schrottky, 1910) (Anthidiini) foram observadas voando na área de estudo e patrulhando alguns ninhos de A. megachiloides, mas sua ocupação não foi registrada.

\section{DISCUSSÃO}

A possibilidade de se ter o ninho das abelhas solitárias enriquece extraordinariamente o conhecimento da espécie, pois, é possível acompanhar e responder perguntas sobre o seu ciclo biológico e desenvolvimento (Krombern 1967, Campos 2000). Com a captura de $A$. megachiloides em ninhos-armadilha em São Paulo foi possível obter alguns dados sobre o seu ciclo reprodutivo, arquitetura interna do ninho e inimigos naturais.

\section{A construção do ninho}

Entre os Megachilidae existe uma gama de materiais que podem ser utilizados para construir ninhos como: folhas e pétalas em espécies de Megachile Latreille 1802 e de Osmia Panzer 1806, barro em espécies de Prochelostoma, fibras de algodão e secreções extraflorais em espécies de Afranthidium Michener 1948, Pseudoanthidium Friese 1898 e de Anthidium Fabricius 1805, ou resina em espécies de Heriades Spinola 1808, Chalicodoma Lepeletier 1841, Anthodioctes Holmberg 1903 e vários Anthidiini, que pode ser pura ou combinada com seixos, solo, lascas de madeiras ou pedaços de vegetais (FIscher 1951, KRombein 1967, Müller et al. 1996, Michener 2000, Morato 2001). A resina possui potencial hidrofóbico, antimicrobial e repelente de inseto (GHISAlbERTI 1979). A utilização deste material na construção do ninho é amplamente difundida entre os diversos gêneros de Anthidiini, bem como entre os Meliponini e Euglossini (RoubIK 1989, Garófalo et al. 1993). RoubiK (1989) chama atenção para o fato que membros de Megachilidae carregam a resina na mandíbula, possibilitando assim que a fêmea transporte pólen na mesma viagem, já que este é carregado na escopa abdominal. Entre os membros da família Apidae a coleta destes dois materiais em uma mesma viagem de forrageamento não seria possível pois, o pólen e a resina são transportados na escopa ou corbícula da perna posterior (RouBIK 1989).

Alguns autores separam os Anthidiini em dois grandes grupos quanto, entre outros caracteres, ao material utilizado na construção do ninho. O primeiro grupo, no qual está inserido Anthodioctes Holmberg, 1903, contem as espécies dos gêneros que fazem ninhos com resina, enquanto que no segundo grupo estão as espécies dos gêneros que utilizam em sua maioria fibras, como pêlos das plantas para este fim (PAsteELS 1977, MÜller 1996, Michener 2000).

Em outubro de 2002 foram encontrados em Campinas alguns ninhos de $A$. megachiloides construídos em um ninho antigo inativo de uma espécie de Brachymenes Giordini Soika 1961 (Vespidae) feito de barro (Alves dos Santos obs. pessoal). Isso demonstra que, na procura por cavidades ou sítios para 
nidificação esta espécie de Anthidiini não é tão exigente quanto ao substrato. Mas, pôde-se notar constância quanto à arquitetura interna e na utilização de resina para a construção das células. Em ambos (ninhos na madeira e no barro), as células apresentaram seqüência linear e o orifício de entrada apresentava caracteristicamente uma larga mancha de resina além de seu limite. A ocupação de ninhos de barro abandonados de vespas solitárias também foi relatada em outras espécies de Anthiidini como, Hypanthidioides arenaria Ducke, 1907 (Laroca \& Rosado Neto 1975) e Anthodioctes manauara Urban, 1999 da região amazônica (Morato 2001).

Quanto ao comportamento de visita aos ninhos antigos, já fechados, acredita-se que nesse momento as fêmeas estariam verificando o estado da resina, ou seja, se está completamente endurecida e se não há furos ou sinais de rompimento. Porém, é possível que seja para a remoção de pequenas porções de resina (mesmo endurecida) para construção de ninhos novos, já que algumas fêmeas foram observadas retirando resina de ninhos abandonados ou antigos. Existe ainda a possibilidade da desorientação do vôo, ou seja, um condicionamento na direção do vôo para um ninho que durou vários dias para estar pronto. Alguns biotestes seriam necessários para interpretar adequadamente deste comportamento intrigante.

\section{Parasitismo}

Os inimigos naturais das abelhas da família Megachilidae são vários. Entre eles temos besouros da família Meloidae, espécies de dípteros do gênero Anthrax Scopoli, 1763 (Bombyliidae) e Phalacrotophora Enderlein, 1912 (Phoridae), espécies de abelhas do gênero Coelioxys Latreille, 1809 e Stelis Panzer, 1806 (Megachilidae), e diversos grupos de vespas como Chrysididae, Chalcidoidea, Leucospidae, Muttilidae, Melittobia (Eulophidae) e Sapygidae (Krombein 1967, Roubik 1989, Morato 2001). A família Sapygidae contém cerca de 80 espécies, sendo todas parasitas de abelhas (WrTt 1998). Espécies do gênero Sapyga são particularmente associadas à família Megachilidae, como por exemplo, Osmia, Heriades, Chelostoma Latreille, 1809, Chalicodoma, Megachile e Anthidiini (Krombein 1967, Torchio 1972, 1989, Münster-Swendsen \& Calabuig 2000). Torchio (1972) estudou em detalhe a biologia de Sapyga pumila Cresson, parasita de ninhos de Megachile rotundata, demonstrando que a taxa de parasitismo pode ser chegar a 77\%. Em várias células Товсніо (1972) encontrou mais do que um ovo de $S$. pumila. MünsterSwendsen \& Calabuig (2000) notaram que a presença de células vazias entre as células de cria de Chelostoma florisomne (Linnaeus, 1758) pode significar uma boa proteção ao sucesso reprodutivo da hospedeira; sendo, portanto considerada como estratégia de defesa contra ataques de Sapyga clavicornis (Linnaeus, 1758). Neste caso, o parasita perfura a parede de barro fresco e deposita seu ovo em um espaço vazio. Células vazias também foram registradas em A. megachiloides, porém não foi possível neste estudo avaliar a eficiência desta estratégia, já que nenhum ovo de parasita foi registrado nas mesmas. Pela disposição das células vazias (em posição distintas dentro do ninho), acredita-se que a construção das mesmas ocorra quando a atividade do parasita é mais intensa. Morato (2001) registrou em A. moratoi Urban, 1999 a presença de células vazias de diferentes tamanhos todas localizadas no final da série de células provisionadas, ou seja, antes do tampão de fechamento.

No presente estudo, a vespa da família Sapygidae não parasitou outras espécies de abelhas e vespas que fundaram ninhos em armadilhas oferecidas no local (Alves dos SANTos 2003). Seu comportamento de patrulha e parasitismo foi específico para A. megachiloides.

Anthodioctes megachiloides também sofreu ataques de uma espécie não identificada de Melittobia em São Paulo. Em anos anteriores a este estudo, essa espécie de vespa parasitóide não tinha sido registrada na área. Porém, em 2001 ocorreu uma proliferação atacando praticamente todas as espécies de vespas e abelhas ocupantes dos ninhos-armadilhas e aumentando consideravelmente a taxa de mortalidade em todas as espécies (Alves-dos-Santos 2003). Parasitas do mesmo gênero também foram registrados em outros Anthidiini (KROMBEIN 1967) e podem ser considerados nocivos para muitas abelhas e vespas solitárias. Morato (2001) registrou 52\% de mortalidade dos imaturos de $A$. moratoi, relacionando esta taxa mais aos ataques de fungos e manuseio dos ninhos, já que apenas uma única célula foi parasitada por díptero da família Phoridae.

\section{AGRADECIMENTOS}

Este trabalho é dedicado a Danúncia Urban, professora e pesquisadora do Departamento de Zoologia, Universidade Federal do Paraná, pela passagem do seu aniversário de 70 anos, muitos dos quais intensamente dedicado à sistemática das abelhas brasileiras. Agradeço a colaboração de Vandré Venitelli e Fernando Belmonte pelo auxílio da confecção dos ninhos armadilhas e observações, Jim Carpenter pela indetificação do Sapygidae, Danúncia Urban pela identificação dos Anthidiini, marceneiros do Instituto de Biociências da USP pela confecção dos ninhos-armadilhas, e ao Laboratório de Abelhas do IBUSP pelas facilidades proporcionadas.

\section{REFERÊNCIAS BIBLIOGRÁFICAS}

Alves dos Santos, I. 2002. A vida de uma abelha solitária. Ciência Hoje, Rio de Janeiro, 179: 60-62.

2003. Trap-nesting bees and wasps on the University Campus in São Paulo, Southeastern Brazil (Hymenoptera, Aculeata). Journal of the Kansas Entomological Society, Lawrence, 76 (2): 328-334.

Alves dos Santos, I.; M.F. Camarotti de Lima; C.F. Martins \& E.F. Morato. (in press). Nesting biology of some Brazilian Anthodioctes species Holmberg 1903 (Anthidiini, Megachilidae). Anais do VI Encontro sobre Abelhas de Ribeirão Preto, $8^{\text {th }}$ IBRA Conference on Tropical Bees. Ribeirão Preto.

Bosch, J.; N. Vicens \& M. Blasm. 1993. Analisis de los nidos de algunos Megachilidae nidificantes en cavidades preestabele-

Revista Brasileira de Zoologia 21 (4): 739-744, dezembro 2004 
cides (Hymenoptera, Apoidea). Orsis, Barcelona, 8: 53-63.

Camillo, E.; C.A. Garófalo \& J.C. Serrano. 1983. Preliminary notes on the biology of Lithurgus huberi (Hymenoptera; Megachilidae) Revista Brasileira de Biologia, São Carlos, 43: 151-156.

. 1994. Nesting activities and nest reuse of Lithurgus huberi (Hymenoptera; Megachilidae). Revista Brasileira de Biologia, São Carlos, 54: 183-194.

Camillo, E.; C.A. Garófalo; J.C. Serrano \& G. Muccillo. 1995. Diversidade e abundância sazonal de abelhas e vespas solitárias em ninhos armadilhas (Hymenoptera, Apocrita, Aculeata). Revista Brasileira de Entomologia, Curitiba, 39 (2): 459-470.

Campos, L.A.O. 2000. Uso de ninhos armadilhas no estudo da biologia de vespas e abelhas que nidificam em orifícios pré existentes e seus associados. Anais do IV Encontro sobre Abelhas de Ribeirão Preto, Ribeirão Preto, 4: 118-120.

Eickwort, G.; R.W. Matthews \& J.M. Carpenter. 1981. Observations on the nesting behavior of Megachile rubi and $M$. texana with a discussion of the significance of soil nesting in the evolution of megachilid bees (Hymenoptera: Megachilidae). Journal of the Kansas Entomological Society, Lawrence, 54: 557-570.

FISCHER, R.L. 1951. Observations on the nesting habits of megachilid bees. Journal of the Kansas Entomological Society 24: 46-50.

Frohlich, D.R. 1983. On the nesting biology of Osmia (Chenosmia) bruneri (Hymenoptera, Megachilidae). Journal of the Kansas Entomological Society, Lawrence, 56:123-130.

Garófalo, C.A.; E. Camillo; J.C. Serrano \& J.M.M. Rebêlo. 1993. Utilization of trap nests by Euglossini species (Hymenoptera: Apidae). Revista Brasileira de Biologia, São Carlos, 53 (2): 177-187.

Ghisalberti, E.L. 1979. Própolis: a review. Bee World, Cardiff, 60: 59-84.

Grigarick, A.A. \& L.A. Stange. 1968. The pollen-collecting bees of the Anthidiini of California. Bulletin of the California Insect Survey, Berkely, 9: 1-113.

Koerber, T.W. \& J.T. MedLer. 1958. A trap-nest survey of solitary bees and wasps in Wisconsin, with biological notes. Wisconsin Academic Science of Arts and Letters, Madison, 47: 63-63.

Krombein, K.V. 1967. Trap nesting wasps and bees. Life histories, nests and associates. Washington, D.C., Smithsonian Institution Press, 570p.

Laroca, S. \& G.H. Rosado-Neto. 1975. Notas bionômicas: Hypanthidiodes arenaria (Hymenoptera, Apoidea). Revista Brasileira de Biologia, São Carlos, 35 (4): 847-853.

Recebido em 08.VIII.2003; aceito em 19.VII.2004.
Michener, C.D. 2000. The bees of the World. Washington, D.C., John Hopkins, 913p.

Morato, E.F. 2001. Biologia e ecologia de Anthodioctes moratoi Urban (Hymenoptera, Megachilidae, Anthidiini) em matas contínuas e fragmentos na Amazônia Central, Brasil. Revista Brasileira de Zoologia, Curitiba, 18 (3): 729-736.

Münster-Swendsen, M. \& I. Calabuig 2000. Interaction between the solitary bee Chelostoma florisomne and its nest parasite Sapyga clavicornis - empty cells reduce the impact of parasites. Ecological Entomology, London, 25: 63-70.

MülLER, A. 1996. Host-plant specialization in western paleartic Anthidiine bees (Hymenoptera: Apoidea: Megachilidae). Ecological Monographs, Washington, D.C., 66 (2): 235-257.

Müller, A.; W. Töpfl \& F. AMiet. 1996. Collection of extrafloral trichome secretions for nest wool impregnation in the solitary bee Anthidium manicatum. Naturwissenschaften, Heidelberg, 83: 230-232.

Parker, F.D. 1987. Nests of Callanthidium from block traps (Hymenoptera, Megachilidae). Pan-Pacific Entomologist, San Francisco, 63: 125-129.

PAsteels, J.M. 1977. The Megachilini parasites (Coelioxys) of tropical Africa. Genera and subgeneric subdivisions. Revue de Zoologie africaine, Tervuren, 91: 161-197.

RichaRds, K.W. 1984. Alfafa Leafcutter Bee Management in Western Canada. Ottawa, Research Branch. Agriculture Canada, Publication 1495E, p. 1-30.

Richards, K.W. 1993. Non Apis bees as crop pollinators. Revue Suisse de Zoologie, Geneva, 100: 807-822.

RoubIK, D.W. 1989. Ecology and Natural History of Tropical Bees. Cambridge Tropical Biology Series, Cambridge University Press, 514p.

Torchio, P.F. 1972. Sapyga pumila Cresson, a parasite of Megachile rotundata (F.) (Hymenoptera: Sapygidae; Megachilidae). Melanderia, Pullman, 10: 1-22.

- 1976. Use of Osmia lignaria Say (Hymenoptera: Apoidea, Megachilidae) as a pollinator in an apple and prune orchad. Journal of the Kansas Entomological Society, Lawrence, 49 (4): 475-482.

. 1989. In-nest biologies and development of immature stages of three Osmia species (Hymenoptera: Megachilidae). Annals of the Entomological Society of America, Lanham, 82: 599-615.

Tscharntke, T.; A. Gathmann \& I.S. Dewenter. 1998. Bioindication using trap-nesting bees and wasps and their natural enemies: community structure and interactions. Journal of Applied Ecology, London, 35: 708-719.

WitT, R. 1998. Wespen beobachten, bestimmen. NaturbuchVerlag, Augsbrug. 360p. 